\title{
Spanish budget raises postdoc job hopes
}

[BARCELONA \& MADRID] After a number of lean years, Spanish science is set to expand. The government's proposed budget, which will be presented to parliament this week, contains significant funding increases to both basic and applied research.

Funding for Spain's National Plan, which provides money for targeted research, will be increased by eight per cent, and the national research council CSIC, which runs 96 basic research institutes, by nearly six per cent. At the same time, by dangling the prospect of new research positions, the government is offering a glimmer of hope for Spain's army of foreign-trained postdoctoral fellows, hundreds of whom face unemployment by the end of the year.

The proposed increases go some way to re-establishing Spain's efforts in the 1980s to create a strong research base. Research spending was doubled by 1990, even though the level reached -0.84 per cent of gross national product - was still well short of the European Union's mean of 1.9 per cent, Spain's ultimate goal.

Research budgets have since stagnated, and next year's planned rise would in real terms return the budget only to its 1994 level. The election promises of the right-wing government, which ended the 13-year run of socialist rule in May last year, that it would restart growth in research spending, were not kept for 1997. But the upturn in Spain's economy has eased the brakes.

The change in fortunes will mean more temporary jobs for scientists through the National Plan, which for the first time will allow its grants to be partly used for payment of salaries. The budget will not in itself mean more permanent research positions. But the government has also promised to support a request from CSIC's president, César

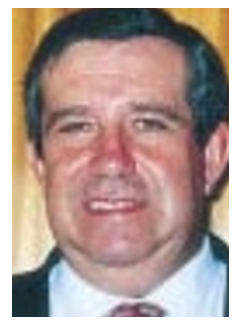

Aldana: stresses industrial links.
Nombela, for the creation of 150 new CSIC research positions next year.

Salaries for permanent researchers come from a central pool reserved for all civil servants. This year, CSIC managed to secure 10 per cent of all new positions earmarked for highly qualified personnel. But because of the strict limit on total numbers, these amounted to only 30 junior, and 20 senior, posts.

Jesus Maria Gonzales, the new secretary of state for universities and research, says that CSIC is likely to do better in 1998. "The government is prioritizing new research positions, and I very much favour plans to introduce new blood into CSIC," he says.

The new positions, if they materialize in full, will help alleviate the problem of the hundreds of young scientists sent abroad on research fellowships in the 1980s as part of the plan to build up national research expertise. They returned as skilled scientists, only to find that the bubble had burst. There were few openings in CSIC, while universities had developed staffing problems and were not hiring staff from outside their own institutions (see box below). Industry showed little interest in hiring specialized scientists.

In 1992 the government made a one-off offer of 1,400 three-year contracts, hoping that this would solve the problem. When it did not, 100 of these were extended for up to two years. At present, 20 per cent of CSIC scientific staff are on such contracts, all of which are now coming to an end.

The contracts are linked to research grants held by tenured members of public research institutes, a point that has been

\section{University rectors join task force on reforms}

[BARCELONA \& MADRID] Spanish university rectors last week accepted an offer from Esperanza Aguirre, the education and culture minister, to take part in a task force with ministry officials to clarify the main problems facing Spanish universities, namely the control of university curricula and the employment structure of academic staff.

The agreement could end a long battle within the ministry, and between the minister and the Spanish University Rectors'
Conference. Last July saw the resignation of Fernando Tejerina, secretary of state for universities and research, who had sided with the rectors, and three other senior ministry officials.

Universities are frustrated by Aguirre's unwillingness to discuss reforms to laws on universities passed in 1983 The rectors want a modified law to enable them to take over control of curriculum design from central government, and to regularize the employment conditions of 23,000 teaching staff hired on short-term contracts in the 1980s. The rectors also want a system of tenure track positions.

Aguirre has promised to issue a universities' policy by the end of the year. According to the new secretary of state for universities and research, Jesus Maria Gonzales, this is likely to include changing academic selection procedures to encourage more competition between universities, and to recruit outside their own institutions and localities.

A.A. criticized by young scientists and many of their senior colleagues, who have been campaigning for independent research positions. Nombela would like to change the career structure of CSIC to make such tenure track positions possible. "But it can't work like that in Spain at the moment," he says. The government is reviewing the inflexible system of civil service employment, but reform is unlikely in the next few years.

Disillusioned young scientists are starting to leave research. Monserrat Vendrell, for example, who worked as a postdoctoral fellow for four years at the Roche Institute in the United States before returning to Spain in 1992, has recently left research for a more certain career in science communication. Josep Casalviserta, who has been surviving on contracts at CSIC institutes in Barcelona since returning from France in 1995, says he will leave research next year if the proposed new openings at CSIC do not materialize.

Many established scientists are upset at the threat the loss of expensively trained personnel could pose to the future of their country's science. According to Mariano Estaban, director of CSIC's National Centre for Biotechnology in Madrid, the push for science in the 1980s went far towards establishing the international credibility of Spanish researchers. Credibility will be lost for ever, he fears, if that investment is now dissipated.

But several temporary measures are being set up. In addition to enabling the National Plan to give grants covering personnel costs, the government has made the plan responsible for administering a Pts28 billion (US\$190 million) grant from the European Social Fund - part of the European Union's structural funds for subsidizing poorer regions - which is intended to forge links between academics and industry.

Part of this money, which must be spent in 1998 and 1999, will subsidize the salaries of up to 200 young scientists, each within six years of completion of his or her $\mathrm{PhD}$, to work in research in industry. A similar scheme launched last year by the government of the autonomous region of Catalonia resulted in two-thirds of participating young scientists being offered permanent positions in their companies.

Fernando Aldana, director of the National Plan, has little sympathy for the plight of the postdocs trained abroad. "They make a lot of noise, but their numbers are small," he says. Reflecting Spain's new emphasis on research with immediate industrial applicability, and the tensions this has created between basic researchers and policymakers, he says that Spain's priorities should not be dictated by the skills the postdocs acquire abroad.

A lis on A bbott 